\title{
A psicanálise na vida cotidiana com as crianças
}

LAJONQUIÈRE, L. Figuras do infantil, São Paulo: Vozes, 2010. $272 \mathrm{p}$.

Marcia Regina Fogaça*

Entrelaçada com retomadas e ressignificaçóes de teses que vem apresentando - e generosamente compartilhando com todos que dele se aproximam -, tais como a concepção de educação como "transmissão de marcas simbólicas" que possibilitam à criança conquistar "um lugar numa história, mais ou menos familiar, e, dessa forma, poder se lançar às empresas do desejo" (p. 63), Leandro de Lajonquière apresenta, em Figuras do infantil, mais uma ideia que podemos considerar uma noção, tal como a expressão "discurso (psico)pedagógico hegemônico", por ele cunhada há uma década.

Desta feita, trata-se da noção de $A$-Criança ${ }^{1}$, que vem trazer em seu bojo a depuração, o refinamento das reflexôes do autor acerca da educação por ele pensada, tendo no horizonte um para "além do gozo pedagógico hegemônico" (p. 56). Visada que, tal como afirma Lajonquière, já estava em Freud, em sua esperança quanto a uma educação para a realidade, como forma de intervenção dos adultos junto às crianças - esperança de que "os adultos pudessem vir a endereçar a palavra às crianças em nome de outra coisa que a moral de seu tempo" (p. 56) que, em nosso tempo, assumiu a forma de um "justificacionismo psicológico: tudo o que acontece na vida junto às crianças - seja em casa, seja na escola - é decifrado e justificado graças a uma hermenêutica psico-sóciológica qualquer" (p. 62, grifo do autor). $\mathrm{Na}$ contramão dessa tendência hegemônica, a educação para a realidade visa ao desejo, e a colocação deste em cena faz com que a questão surgida da relação entre psicanálise e educação ganhe complexidade na medida em que, ao contrário da opinião de muitos que a pensam em termos de aplicação da primeira em relação à segunda, o autor conclui que cabe melhor falar em "psicanálise na educação", na medida em que

\footnotetext{
* Professora da Faculdade Itapecerica da Serra (FIT) e membro do Laboratório de Estudos e Pesquisas Psicanalíticas e Educacionais sobre a Infância (LEPSI) do Instituto de Psicologia e Faculdade de Educação da Universidade de São Paulo, Brasil.mfogaca@usp.br

I. Mantenho o itálico que o autor utiliza todas as vezes que a expressão aparece no texto.
} 
se trata de "analisar, dissolver, as ilusões tecnocientificistas que imperam no campo educativo com vistas à educação para a realidade impossível do desejo" (p. 71). Nesse sentido, cabem as perguntas: "levar as crianças a reconhecer que o desejo ultrapassa as forças de nosso corpo, bem como extrapola o tempo exíguo de nossas vidas, constitui de fato uma meta pedagógica?” e, em sendo assim, "quais os meios para ela ser atingida?".

Não é difícil supor, para aqueles que seguem o texto atentamente, ainda que o tema não lhes seja familiar, que a resposta à primeira pergunta é não. No entanto, o porquê do não não deixa de surpreender, por sua verdade contundente e simples obviedade: porque, quando se trata de desejo, não se está no campo da especialidade/pedagogia e, sim, daquilo que é comum/educação, ou seja, "Educar para a realidade ou educar para o desejo é aquilo que o homem comum sabe fazer - embora sem o saber - desde sempre quando se trata de crianças". (p. 64). No entanto, em não sendo uma meta pedagógica, é uma meta educativa que se atinge "endereçando a palavra a uma criança", ou seja, dando-se testemunho da castração, da sujeição à linguagem - única forma de produzir efeitos subjetivantes na criança. E é aí, justamente, que mora o perigo, pois, para escapar dessa posição de assujeitamento e castração, os adultos impregnam a educação de pedagogia, lançando mão de saberes especializados sobre a criança. Saberes que se apresentam como um "fundamentalismo naturalista" que fazem: da educação, "um processo mais ou menos complexo de estimulação ou interação meio/socius-organismo" (p. 68); da criança, "objeto de saberes especializados de natureza psicomédica" (p.68); e das "vicissitudes da vida em companhia das crianças, [...] o desenvolvimento de uma racionalidade didático-instrumental imanente ao real" (p. 68). Resultado: interrogar o impossível em torno do qual se articula a relação do adulto com a criança torna-se algo, como diria o autor, de difícil acontecimento.

Da distinção entre educação e pedagogia, apresentada por Lajonquière como resultado de atenta leitura de textos freudianos, decorre a afirmação de que "o sujeito da educação não é outro que o sujeito do desejo..." (p. 79) e que, portanto, a educação deve ser pensada "no interior do campo da palavra e da linguagem animada pelo desejo e, dessa forma, colocar em relevo o seu estofo de laço social" (p. 78). Seus argumentos refletem sua experiência como psicanalista e, fundamentalmente, como professor de futuros professores, a quem endereça a palavra, deixando que sua (da palavra) mestria se cumpra "à revelia das contingências do ensino universitário" (p.26). Experiência que transparece sensivelmente no árduo trabalho teórico apresentado no texto. É justamente no vai e vem, entre experiência e trabalho teórico, que surge a noção de $A$ Criança, aporte fundamental ao campo em questão e um avanço teórico sobre questôes que o autor vem trabalhando ao longo de anos, em torno da incidên- 
cia do discurso da psicologia sobre a pedagogia, que resultou na ilusão alimentada pelo "discurso (psico) pedagógico hegemônico". Discurso esse que continua a fazer seus estragos, contribuindo para a "naturalização violenta da infância, via império do tecnocientificismo médico-psico-pedagógico pão-nosso da vida cotidiana" que "nas últimas décadas, deu lugar a um fantasma singular que ultrapassa toda divisão societária: A-Criança" (p. 19) - um derivado do império da ilusão desse mesmo discurso.

Embora tal discurso se tenha acirrado nas últimas décadas, Lajonquière localiza sua origem na virada do século XVIII, "quando o saber pedagógico, entrelaçado com a nascente psiquiatria e a filosofia do Iluminismo, adquiriu uma fisionomia tal que se tornou paradigma para as gerações futuras de 'especialistas na educação e re-educação de crianças'." (p. 122). De origem positivista, tal saber se converte "em ideologia hegemônica no campo pedagógico, expande-se mascarado com o véu da naturalidade dando, assim, lugar ao discurso (psico)pedagógico hegemônico"(p. 122, grifo do autor), cujo pioneiro, Jean Itard², revisitado por nosso autor, é considerado a encarnação do "furor pedagógico que não reconhece a impossibilidade da educação" (p. 141) e que, portanto, articula-se a partir da recusa do sujeito do desejo e, portanto, da castração. Com Itard perfilam-se Shereber, Frankenstein e todos aqueles que, depois deles, sonham com estímulos, necessidades a serem satisfeitas e uma "educação ao abrigo das vicissitudes da filiação e da infância" (p. 191).

Por outro lado, há a história de Anne Sullivan e Helen Keller ${ }^{3}$ ou a história do encontro de uma educadora quase cega com uma menina cega e surda, que coloca em cena aquilo que Itard não pôde fazer por Victor, em virtude de sua recusa do desejo /castração: o endereçamento da palavra à criança que lhe permitiu a sujeição ao discurso. Em outras palavras, enquanto Itard se colocou como especialista de necessidades que fala da criança, Hellen Keller colocou-se como "gente comum" /desejante, que dá testemunho da castração, da sujeição ao Outro, ao falar com a criança. Victor não chegou nunca a falar, ao contrário de Hellen Keller - ambos enquadráveis na contemporânea e supostamente mais humana e científica categoria de "crianças com necessidades especiais", outrora possíveis deficientes mentais, idiotas, imbecis e débeis mentais.

A categoria de "crianças com necessidades educativas especiais", na qual se encaixam as mais diversas "necessidades", evidencia que não só de crianças "nor-

2. Os relatórios do tratamento médico-pedagógico dado a Victor, criança encontrada, na década de 1810 , em Aveyron, França, em estado "selvagem", que levou à discussão da possibilidade de sua educação e adaptação à vida civilizada, podem ser lidos em BANKS-LEITE, L; GALVÃO, I. A educação de um selvagem. São Paulo: Cortez, 2001 .

3. Retratado no filme de Arthur Penn (1962), exibido no Brasil com o título de O milagre de Anne Sullivan. 
mais" vive o ideário pedagógico. Ideário que, visando dar conta da selvageria, da idiotice, da deficiência, das necessidades e, principalmente, da "mesmíssima" infância - outro dos "nomes de nossa estrangeirice" que nos retorna do des(encontro) com uma criança -,edifica-se e mantém-se sobre o pano de fundo $\mathrm{d} A$-Criança: "Esse ser natural, dotado de direitos e necessidades educativas mais ou menos especiais, porém sempre clamante de satisfação" que "virou parâmetro comportamental onipresente na vida junto a esses seres pequenos, que temos o hábito, até agora, de chamarmos de crianças" (p. 19).

Encarnação da criança lançada fora do laço social em função de uma suposta excepcionalidade, para além da estrangeirice "normal" - um dos lados da mesma fita de Moebius que comporta o familiar a que toda criança deve aceder -, A-Criança é falada, ninguém fala com ela. Essa diferença fundamental é resultado da impossibilidade de um adulto em "desdobrar" o retorno do infantil, ou seja, do desejo/inconsciente/sexual/incestuoso que se apresenta no (des)encontro com uma criança. Parece mais fácil falar d'A-Criança que com a criança - que implica o reconhecimento por parte desse adulto de sua própria infância recalcada.

Em dado momento de seu texto, Leandro afirma que, talvez, o caráter inconcluso de uma suposta tese freudiana acerca da educação alimente e funcione como causa de busca de elucidação. Em sendo assim, pode-se dizer que seu próprio texto assume esse mesmo caráter do texto freudiano ao testemunhar com coragem sua inscrição numa linhagem aberta e inconclusa de permanente invenção acerca do mesmo, na qual não se pode furtar à "experiência de simbolização d'isso mesmo que resta no interior do campo da palavra e da linguagem e do qual o sujeito goza" (p.43, grifo do autor). Talvez, por isso, Figuras do infantil poderia bem ter sido concluído com a seguinte questão:

Quando um velho endereça a palavra a uma criança, instaura-se a possibilidade da produção psíquica de um tempo de infância e, portanto, da renovaçáo da diferença estrangeiro/familiar no nosso mundo cotidiano. Por que podemos vir a ocupar uma posição educativa perante esses seres pequenos?"(ibidem, p. 260, grifos do autor). 